\title{
A FORMAÇÃO DOS PROFESSORES QUE ENSINAM FÍSICA NO ENSINO MÉDIO
}

\section{Training of teachers in High School physics}

Cintia Aparecida Bento dos Santos ${ }^{1}$. Edda Curi ${ }^{2}$

Resumo: Este artigo apresenta dados coletados em nossa pesquisa de doutorado. Temos por objetivo refletir sobre o quadro referente à formação dos professores que ministram a disciplina de física no Ensino Médio. Analisamos dados do Mec/Inep sobre a formação dos professores que ministram a disciplina de física no Brasil e do Censo Escolar da Educação Básica. Constatamos que os professores que ministram a disciplina de física no Ensino Médio são, na maioria, licenciados em matemática; e, levando em consideração autores que discutem a formação de professores, analisamos as ementas das disciplinas de física, bem como sua carga horária e os conteúdos ministrados em 27 cursos de licenciatura em matemática de instituições de Ensino Superior. Concluímos que os dados são preocupantes, pois, além de serem poucos os professores com formação específica na área de física, os demais docentes que ministram esta disciplina não têm formação adequada para atuar nessa área do conhecimento.

Palavras-chave: Formação de professores. Ensino Médio. Ensino de física.

Abstract: This article presents collected data from our doctoral research; we aim to reflect on the scenario for the training of teachers who teach the discipline of Physics in high school. We analyzed data from Mec/Inep on the training of teachers who teach the discipline of Physics in Brazil and in the Basic Education School Census. We noted that teachers who teach the discipline of Physics in high school have mostly majored in Math and, taking this into consideration the authors discuss the teachers' training. We noted the menus of the disciplines of Physics, as well as its workload and the subjects taught in 27 undergraduate programs in Mathematics from higher education institutions. We concluded that the data are worrying because, besides there being only a few teachers with specific training in Physics, the other teachers who teach this subject do not have adequate training to teach in this area of knowledge.

Keywords: Teacher training. High School. Physics teaching.

1,2 Programa de Pós-Graduação em Ensino de Ciências e Matemática, Universidade Cruzeiro do Sul, São Paulo, SP, Brasil. Rua Galvão Bueno, 868, sala 1003, Liberdado. São Paulo, SP, Brasil. 01-506-000.

cintia.santos@cruzeirodosul.edu.br 
Santos, C. A. B.; Curi, E.

\section{Introdução}

Este artigo é um recorte da pesquisa de Santos (2010), realizada para tese de doutorado, cujo objetivo era evidenciar as potencialidades e as limitações que o domínio de conhecimentos matemáticos gera para aprendizagem de física no Ensino Superior. Durante nossos estudos, constatamos que a maioria dos professores que ministram a disciplina de física no Ensino Médio tem sua formação específica no curso de licenciatura em matemática. Por esse motivo, realizamos uma análise, a fim de verificar como esses professores recebem formação nas disciplinas de física, uma vez que, eventualmente, podem ministrar esta disciplina no Ensino Médio. Apresentaremos, aqui, os dados coletados e as análises realizadas a partir do quadro que aponta para a formação dos professores que ministram a disciplina de física no Ensino Médio no Brasil.

Em nossa própria prática docente, como professora em escolas estaduais da rede de ensino da cidade de São Paulo, observamos uma efetiva carência de profissionais habilitados especificamente na área de física: as aulas desta disciplina quase sempre são atribuídas a profissionais formados em outras áreas do conhecimento.

Esses dados nos levam a supor que, para suprir esta carência, professores formados em outras áreas, como os licenciados em matemática, acabam por assumir aulas de física. Considerando a legislação sobre atribuição de aulas no estado de São Paulo, de acordo com o artigo 45 da Lei Complementar no 444/ 85 (SÃO PAULO, 1985), que tem como base a Indicação CEE no 53/2005 (SÃO PAULO, 2005a), o curso de licenciatura plena em matemática tem, como disciplina específica, a matemática, e como não específica, ou correlata, a física. $\mathrm{O}$ artigo 13 da Resolução SE nº 90/2005 (SÃO PAULO, 2005b) prevê que, observado no histórico de um curso de licenciatura o mínimo de 160 horas de estudos de disciplinas correlatas, é permitida a atribuição de aulas da disciplina correlata. Isso quer dizer que a legislação permite aos licenciados em matemática ministrarem aulas de física, desde que a estrutura curricular de seu curso de licenciatura em matemática tenha contemplado as 160 horas de física.

Porém, sabemos que um curso de licenciatura em matemática tem como objetivo primordial formar professores de matemática, e não de física. Isso é preocupante, pois o professor de física no Ensino Médio necessita de sólida formação específica.

Para evidenciar as considerações que tecemos até o momento, apresentaremos um mapeamento do panorama da formação dos professores que ministram a disciplina de física no Ensino Médio e alguns dados sobre os cursos de licenciatura em física no Brasil, quanto ao seu funcionamento, considerando quantidade de cursos, ingressantes e concluintes. Esses dados foram coletados no sítio do Instituto Nacional de Estudos e Pesquisas Educacionais Anísio Teixeira (Inep), com base na Sinopse Estatística da Educação Superior 2007.

Em prosseguimento, analisaremos os dados do Censo Escolar de 2007, apresentados no documento do Inep "Estudo Exploratório sobre o Professor Brasileiro" (INSTITUTO NACIONAL DE ESTUDOS E PESQUISAS EDUCACIONAIS ANÍSIO TEIXEIRA, 2009b), e a disciplina de física presente nas estruturas curriculares das 27 instituições de Ensino Superior pesquisadas, que se encontram divididas por região demográfica. 
A formação dos professores que ensinam física...

\section{Sobre os cursos de licenciatura de física no Brasil}

O Censo da Educação Superior de 2009, realizado pelo Inep/Mec (INSTITUTO NACIONAL DE ESTUDOS E PESQUISAS EDUCACIONAIS ANÍSIO TEIXEIRA, 2009a), com base nos dados coletados em 2007, permite algumas ponderações a respeito dos cursos de licenciatura em física no Brasil. Esse documento revela que:

- Há, no Brasil, 260 cursos de licenciatura em física.

- Apenas 30\% dos candidatos inscritos no processo seletivo ingressam no curso de licenciatura em física, o que representa a ocupação de, aproximadamente, $57 \%$ das vagas oferecidas pelas instituições no Brasil.

. Era de 12.212 o número de alunos matriculados nos cursos de licenciatura em física em 2007.

. Do total de matriculados, apenas aproximadamente $11 \%$ concluem o curso, ou seja, cerca de 1.342 alunos.

\section{Sobre a formação dos professores que ministram aulas de física no Brasil}

Os dados do Mec/Inep (INSTITUTO NACIONAL DE ESTUDOS E PESQUISAS EDUCACIONAIS ANÍSIO TEIXEIRA, 2009b) revelam a situação atual em relação ao ensino de física. Dos 44.566 professores que ministram a disciplina de física, apenas 12.355 possuem licenciatura nessa disciplina; os demais, em número de 32.211, possuem formação específica em outras disciplinas. O próprio documento do Mec/Inep (INSTITUTO NACIONAL DE ESTUDOS E PESQUISAS EDUCACIONAIS ANÍSIO TEIXEIRA, 2009b) ressalta, em relação a esses dados, que, quando se analisa mais detalhadamente a formação dos professores que ministram a disciplina física, chama a atenção o elevado número - da ordem de 15.170 - de docentes com formação em matemática, o que corresponde a 34\% dos 44.566 docentes da disciplina, um conjunto bem maior do que os 12.355 professores com formação em física.

A situação é, de fato, bastante grave, pois a esse contingente se adicionam os licenciados em outras áreas, inclusive Pedagogia. Com base nos dados do documento do Mec/Inep (INSTITUTO NACIONAL DE ESTUDOS E PESQUISAS EDUCACIONAIS ANÍSIO TEIXEIRA, 2009a), organizamos o Quadro 1, em que relacionamos a área de formação e a área de atuação dos professores brasileiros nas disciplinas de física e matemática.

Quadro 1. Número de professores do Ensino Médio por disciplina que lecionam, segundo área de formação, em 30/05/2007

\begin{tabular}{|l|cc|}
\hline \multirow{2}{*}{ Área de formação } & \multicolumn{2}{|c|}{ Disciplina que lecionam } \\
\cline { 2 - 3 } & Física & Matemática \\
\hline Matemática & 15.170 & 39.285 \\
\hline Física & 11.238 & 2.074 \\
\hline
\end{tabular}

Fonte: Instituto Nacional de Estudos e Pesquisas Educacionais Anísio Teixeira (2009a) 
Santos, C. A. B.; Curi, E.

O Quadro 1 indica que há mais professores de matemática ministrando a disciplina de física do que docentes com habilitação específica em física. Os dados apresentados até o momento mostram que, para suprir a demanda de professores de física, são necessários 44.566 professores, e temos, na verdade, dentro da rede de Educação Básica, apenas 12.355 docentes com formação específica em física. Como já foi constatado, há pouca quantidade -1.342 - de professores formados nessa área. Se considerarmos que essa proporção se mantenha constante nos próximos anos e que todos os concluintes ingressem na rede básica de ensino, teremos mais de vinte anos para que todos os professores do Ensino Médio tenham a formação específica, isso se o número de aulas de física nesse segmento de ensino não se ampliar nos próximos anos, já que a tendência de ampliar a oferta de cursos de Ensino Médio é uma realidade hoje.

O documento Mec/Inep (INSTITUTO NACIONAL DE ESTUDOS E PESQUISAS EDUCACIONAIS ANÍSIO TEIXEIRA, 2009b) explicita que o percentual de $25 \%$ de professores formados em física que atuam no Ensino Médio se amplia para cerca de $40 \%$, quando se incluem os formados em Ciências Físicas.

A Tabela 1, elaborada com dados do documento do Mec/Inep (INSTITUTO NACIONAL DE ESTUDOS E PESQUISAS EDUCACIONAIS ANÍSIO TEIXEIRA, 2009c), indica as áreas em que são formados os professores que ministram a disciplina de física no Ensino Médio.

\begin{tabular}{|c|c|c|c|}
\hline \multirow[b]{2}{*}{ Disciplina } & \multirow[b]{2}{*}{ Área de formação dos professores } & \multicolumn{2}{|c|}{ Total } \\
\hline & & $n^{\circ}$ & $\%$ \\
\hline \multirow[t]{6}{*}{ Física } & Total & 44.566 & 100,0 \\
\hline & Física & 11.238 & 25,2 \\
\hline & Matemática & 15.170 & 34 \\
\hline & Área específica (Ciências Físicas) & 6.340 & 14,2 \\
\hline & Pedagogia & 2.636 & 5,9 \\
\hline & Outras áreas & 9.182 & 20,6 \\
\hline
\end{tabular}

Fonte: adaptado de Instituto Nacional de Estudos e Pesquisas Educacionais Anísio Teixeira (2009c)

Visto que grande parte dos professores de matemática atua na disciplina de física no Ensino Médio, passaremos a investigar, no próximo item, a análise de estruturas curriculares de cursos de licenciatura em matemática em relação às disciplinas de física.

\section{Sobre os cursos de licenciatura em matemática analisados e sua estrutura curricular em relação às disciplinas de física}

Este estudo sobre a organização das disciplinas de física dos cursos de licenciatura em matemática de 27 instituições de Ensino Superior distribuídas pelo Brasil, escolhidas ale- 
A formação dos professores que ensinam física...

atoriamente na internet por meio do acesso ao site das instituições, deu prioridade àquelas que disponibilizam em sua página o projeto pedagógico do curso. A partir do estudo das estruturas curriculares e das ementas, elaboramos as categorias de análise, considerando, por região demográfica, um número igual ou próximo entre Instituições de Educação Superior (IES), quanto à categoria administrativa - estadual, privada e federal. As categorias de análise foram estabelecidas com base nos seguintes critérios: carga horária das disciplinas oferecidas; organização anual ou semestral da disciplina ministrada; conteúdos propostos nas ementas das disciplinas, considerando, ainda, a presença de abordagem didática desses conteúdos de aulas de laboratório.

Para análise dos conteúdos e de suas didáticas, utilizamos estudos de autores que discutem a formação dos professores, em especial o conhecimento do professor.

\section{Com relação ao tipo de instituição}

Entre as instituições pesquisadas, dez são de cunho federal, oito são estaduais e nove são da rede particular de ensino.

\section{Com relação à organização das disciplinas de física}

Metade das instituições pesquisadas organiza a(s) disciplina(s) de física em um único semestre, e a outra metade a(s) organiza em dois, três ou quatro semestres, dependendo da carga horária oferecida.

\section{Com relação à carga horária}

A carga horária das disciplinas relativas à física é oferecida nas instituições num único semestre ou em vários semestres, conforme a Tabela 2.

Tabela 2. Carga horária da disciplina de física nos cursos de licenciatura em matemática das IES pesquisadas

\begin{tabular}{lcc}
\hline Organização da disciplina & número de horas & número de instituições \\
\hline 1 semestre & $60-72$ & 3 \\
2 ou 3 semestres & $120-180$ & 14 \\
4 semestres & $>180$ & 10 \\
\hline
\end{tabular}

Fonte: Elaborado pelas autoras

\section{Quanto à presença de aulas de laboratório}

As instituições que incluem aulas de laboratório são as dez que têm carga horária maior que cento e oitenta horas. No entanto, embora em algumas delas as aulas de laboratório sejam destinadas ao ensino de física, o que é bastante importante para a formação do professor, nem sempre essas aulas são destinadas a experimentos que envolvem noções de física. 
Santos, C. A. B.; Curi, E.

\section{Com relação aos conhecimentos de conteúdos}

Para a análise dos conteúdos propostos, recorremos a alguns pesquisadores que discutem a formação de professores. As investigações dos últimos anos revelam que, sem dominar com elevado grau de competência o conteúdo a ser ensinado, o professor não pode exercer de forma adequada sua função profissional. Destacam também que é bastante difícil definir quais os conhecimentos de que o professor realmente necessita e quais as melhores formas de esses conhecimentos serem explorados nos cursos de formação inicial.

Tardif (2002) ressalta que o conhecimento do professor é diferente do conhecimento do especialista na disciplina e tem o foco no saber a disciplina para ensiná-la. $O$ autor destaca, ainda, que os conhecimentos constituídos pelos professores têm origem na sua trajetória pré-profissional como estudantes - no caso do ensino de física, no Ensino Médio. Ele revela que esses conhecimentos influenciam a formação e a prática dos professores.

Esses comentários mostram a complexidade da formação inicial do professor. Para o futuro professor que faz um curso de licenciatura em matemática e tem a possibilidade de ensinar física, essa complexidade é maior ainda. Cabe lembrar que, no início deste artigo, dados mostram que grande parte dos professores que lecionam física são licenciados em matemática.

A análise das ementas das instituições aponta que estas priorizam conteúdos do Ensino Médio: há grande concentração nos conteúdos de cinemática, dinâmica e eletricidade, seguidos de Termologia e calorimetria, com menor enfoque nos conteúdos de ondas e óptica. E um olhar para a bibliografia das referidas ementas leva a conjecturar que é dado a esses conteúdos um tratamento de revisão, sem maiores aprofundamentos (Quadros 2 a 5).

Outro pesquisador que discute a formação do professor é Shulman (1986). Ele focaliza o conhecimento do conteúdo da disciplina a ser ensinada, destacando que o professor deve compreender sob diversas óticas a disciplina que vai ensinar, e fazer relações entre os vários tópicos do conteúdo disciplinar e entre sua disciplina e outras áreas do conhecimento. O autor destaca que, na formação acadêmica da disciplina a ensinar, o conhecimento dos conteúdos deve envolver: sua compreensão e o desenvolvimento de procedimentos, a filosofia e a natureza do conhecimento nesse campo de estudo. Revela, ainda, que o professor deve compreender a estrutura dos conteúdos, os princípios da organização conceitual, entre outros.

Ponte (1992) faz uma consideração importante: destaca que os conhecimentos dos

Quadro 2. Ementa das disciplinas Física I e Física II, da IES 1

\section{Disciplina: Física I}

Ementa: Dimensões. Unidades e conversões. Cinemática: deslocamento, velocidade e aceleração; lançamento de projéteis. Leis de Newton. Aplicações. Força de atrito. Forças fictícias. Trabalho e energia. Teorema da energia cinética. Momento Linear. Conservação do Momento linear. Colisões. Gravitação. Leis de Kepler.

\section{Disciplina: Física II}

Ementa: Oscilações. Estática dos fluidos. Dinâmica dos fluidos. Ondas em meios elásticos. Ondas sonoras. Temperatura. Calor e a primeira lei da termodinâmica. Teoria cinética dos gases. Entropia e a segunda lei da termodinâmica.

Fonte: Disponível em: <http://www.espam.edu.br/index.php?menu=cursos\&curso=10>. Acesso em: 10 set. 2009 
A formação dos professores que ensinam física...

Quadro 3. Ementa das disciplinas Física I e Física II, da IES 3

\section{Física I}

Descrição: Dar conhecimento e compreensão dos fenômenos físicos; analisar fatos do dia a dia com os fenômenos estudados; levar ao raciocínio crítico dos fenômenos; estabelecer relação da Física com outras ciências; tomar contato com o mundo científico; aplicar de forma crítica e desmistificada o aprendizado ao cotidiano; aplicar seu conhecimento sobre os usos e vantagens da mecânica, do calor e sons; realizar experimentos com materiais de fácil acesso.

Ementa: Mecânica, Calor e Acústica.

Física ll

Descrição: Dar conhecimento e compreensão dos fenômenos físicos; analisar fatos do dia a dia com os fenômenos estudados; levar ao raciocínio crítico dos fenômenos; aplicar, de forma crítica e desmistificada, o aprendizado ao cotidiano; aplicar seu conhecimento sobre os usos e vantagens da ótica, da eletricidade e do eletromagnetismo; realizar experimentos com materiais de fácil acesso.

Ementa: Ótica, Eletricidade e Eletromagnetismo

Fonte: <http://www.uems.br/cursos/disciplinas.php?ID=11\&NM=Matemática\&CD=Nova Andradina>. Acesso em: 10 set. 2009

Quadro 4. Ementa da disciplina Física Teórica e Experimental I, da IES 11

Ementa: Padrões e Unidades. Incertezas e Algarismos Significativos. Vetores. Movimento em Duas e Três Dimensões. As Leis Fundamentais da Mecânica. Trabalho e Energia. Momento Linear, Impulso e Rotação de Corpos Rígidos.

Fonte: <http://www.unit.br/cursos/graduacao/matematica/>. Acesso em: 10 set. 2009

Quadro 5. Ementa da disciplina Física Teórica e Experimental II, da IES 11

Ementa: Movimento Periódico. Temperatura, Calor, e As Leis da Termodinâmica; Eletricidade: Carga Elétrica e Campo Elétrico. Capacitância e Dielétricos. Corrente, Resistência e Força Eletromotriz. Eletromagnetismo: Campo Magnético e Força Magnética; Fontes de Campo Magnético.

Fonte: <http://www.unit.br/cursos/graduacao/matematica/>. Acesso em: 10 set. 2009

professores devem incluir os objetivos de ensino, ou seja, os conceitos definidos para o grau de escolaridade com que ele irá atuar, mas devem ir além, no que se refere tanto à profundidade desses conceitos como à sua historicidade, às articulações com outros conhecimentos e ao tratamento didático, ampliando, assim, seu conhecimento de área.

As considerações desses autores não se aplicam às ementas estudadas. Estas, em sua maioria, não ampliam os conhecimentos de conteúdos, mas focalizam-nos como revisão porque, supostamente, já foram estudados no Ensino Médio.

\section{Com relação aos conhecimentos didáticos dos conteúdos a serem ensinados}

Shulman (1986) destaca um tipo de conhecimento especial do professor e denominao de conhecimento didático do conteúdo. Ele o entende como uma combinação entre o conhecimento do conteúdo e o modo de ensiná-lo e fazer os alunos aprenderem. O autor revela que esse tipo de conhecimento permite ao professor ensinar algo em determinado contexto, improvisar perante uma situação, ou elaborar ações pedagógicas. 
Santos, C. A. B.; Curi, E.

Apenas duas das instituições pesquisadas apresentam foco no conhecimento didático, porém as disciplinas com esse foco encontram-se entre as optativas do curso. Uma delas é denominada Laboratório de Ensino de Física Fundamental I, cuja ementa está no Quadro 6.

Quadro 6. Ementa da disciplina Laboratório de Ensino em Física Fundamental I, da IES 15

Ementa: Tópicos selecionados da ementa da disciplina Física Fundamental I.

Objetivos: Promover a articulação da prática de ensino da disciplina Física Fundamental I. Desenvolver a capacidade de comunicar raciocínios e ideias, oralmente e por escrito, com clareza e progressivo rigor lógico. Usar corretamente o vocabulário e a simbologia específicos da física.

Atividades: Sob orientação do professor, os alunos deverão desenvolver atividades de ensino tais como: seminários, palestras, elaboração e realização de projetos acadêmicos, realização de experiências de laboratório. Nestas atividades deve-se também estimular o uso de recursos didáticos, tais como: o computador, retroprojetor, datashow, entre outros.

Fonte: <http://cultura.ufpa.br/matematica/?pagina=licenciatura2>. Acesso em: 10 set. 2009

Os aspectos relacionados à didática no ensino de física são tratados superficialmente nessa disciplina, talvez em razão da carga horária bastante pequena, cerca de trinta horas.

$\mathrm{Na}$ segunda instituição, além das disciplinas obrigatórias, há a oferta de diversas disciplinas de física como optativas. As disciplinas relativas ao ensino de física compõem o bloco IX, conforme o Quadro 7.

Quadro 7. Disciplinas optativas da IES 20

\begin{tabular}{|c|c|}
\hline \multicolumn{2}{|c|}{ Bloco XIII - Física } \\
\hline $\begin{array}{l}\text { Laboratório de mecânica } \\
\text { Mecânica dos corpos rígidos e dos fluidos } \\
\text { Eletricidade II } \\
\text { Oscilações e Ondas } \\
\text { Eletromagnetismo } \\
\text { Laboratório de eletromagnetismo }\end{array}$ & $\begin{array}{l}\text { Termodinâmica II } \\
\text { Evolução dos conceitos de física } \\
\text { Partículas: a dança da matéria } \\
\text { Física do meio ambiente } \\
\text { Conceitos de astronomia para a licenciatura } \\
\text { Relatividade }\end{array}$ \\
\hline \multicolumn{2}{|c|}{ Bloco IX - Ensino de física } \\
\hline $\begin{array}{l}\text { Elementos e estratégias para o ensino da física } \\
\text { Propostas e projetos de ensino de física }\end{array}$ & $\begin{array}{l}\text { Termodinâmica II } \\
\text { Evolução dos conceitos de física }\end{array}$ \\
\hline
\end{tabular}

Fonte: Elaborado pelas autoras

Essa instituição considera que a disciplina de física ministrada no curso de licenciatura em matemática assume vários papéis, sendo um deles a formação mínima para uma complementação que permita aos futuros professores atuarem como docentes de física no Ensino Médio. Considera, ainda, que a importância da articulação entre ambas as disciplinas deve ser evidenciada aos alunos. Seu projeto pedagógico destaca a cobertura que o curso dá aos tópicos de física normalmente desenvolvidos no Ensino Médio, o que permite uma formação mínima para o professor ensinar física, ou ainda, futuramente, cursar disciplinas mais avançadas que fazem uso da matemática. 
A formação dos professores que ensinam física...

No entanto, a organização desse curso, embora apresente algumas disciplinas com foco no ensino de física, não garante a participação dos alunos, por serem elas optativas.

\section{Outras observações com relação às ementas}

A análise das ementas revelou que não há, nesses cursos, nenhuma discussão sobre o currículo de física no Ensino Médio. Shulman (1986) destaca a importância do conhecimento curricular que, segundo ele, engloba: a compreensão do programa, o conhecimento de materiais que o professor seleciona para ensinar, a capacidade de fazer articulações do conteúdo, sua evolução no currículo, entre outros aspectos.

Há outras instituições, além das citadas, que oferecem disciplinas optativas, porém estas são voltadas aos conteúdos da física.

A análise realizada revela, em uma das instituições, uma disciplina denominada física para licenciatura (Quadro 8).

Quadro 8. Ementa da disciplina física para licenciatura, da IES 27

Ementa: Física para licenciaturaMecânica (MRU, MRUV, lançamento vertical e horizontal). As três leis de Newton. Hidrostática (pressão, densidade, Lei de Stevin, princípio de Pascal). Termologia e Calorimetria. Dilatação térmica.

Fonte: <http://www.unimeo.com.br/matematica/estruturacurricular.htm>. Acesso em: 10 set. 2009

Esta é a única disciplina da área de física na estrutura curricular do curso de licenciatura em matemática da IES 27; a ela é destinada uma carga horária total de cento e sessenta horas, dividida em cento e vinte horas para aulas teóricas e quarenta para aulas práticas. Apesar do nome sugestivo e de uma carga horária que excede significativamente as das demais IES aqui analisadas, os conteúdos abordados restringem-se aos campos da Mecânica e da Termodinâmica, sem aprofundamento de outros conteúdos da física nem enfoque em aspectos curriculares e metodológicos, no que se refere ao seu ensino.

Uma instituição revelou-se um caso atípico em relação às outras: nela ocorrem, em todos os semestres, exceto no $4^{\circ}$, disciplinas da área de física, conforme discriminamos no Quadro 9.

Quadro 9. Disciplinas da área de física ministradas semestralmente na IES 17

\begin{tabular}{|c|c|c|}
\hline $\mathbf{1}^{\mathbf{0}}$ semestre & $\mathbf{2}^{\mathbf{0}}$ semestre & $\mathbf{3}^{\circ}$ semestre \\
\hline $\begin{array}{c}\text { Física experimental I } \\
\text { Física geral I } \\
\text { Fundamentos de física I }\end{array}$ & $\begin{array}{c}\text { Física experimental II } \\
\text { Física geral II } \\
\text { Fundamentos de física II }\end{array}$ & $\begin{array}{c}\text { Física experimental III } \\
\text { Física geral III } \\
\text { Óptica e Acústica }\end{array}$ \\
\hline $\mathbf{4}^{\circ}$ semestre & $\mathbf{5}^{\circ}$ semestre & $\mathbf{6}^{\circ}$ semestre \\
\hline- & Física matemática I & Física matemática II \\
\hline
\end{tabular}

Fonte: Elaborado pelas autoras 
Santos, C. A. B.; Curi, E.

Ao analisarmos as ementas dessa instituição, percebemos a preocupação com o aprofundamento dos conteúdos. O objetivo da disciplina de Física Experimental é a articulação entre as teorias trabalhadas e os procedimentos experimentais. Assim, as ementas revelam como princípio trabalhar em laboratório só conteúdos teóricos das disciplinas de Física Geral I, II e III e Fundamentos de Física I e II.

A disciplina de Óptica e Acústica é ministrada separadamente dos demais conteúdos de física, no $3^{\circ}$ semestre, buscando articular a teoria com os procedimentos laboratoriais, conforme descreve sua ementa, apresentada no Quadro 10.

Quadro 10. Ementa da disciplina Óptica e Acústica, da IES 17

Disciplina: Óptica e Acústica

Ementa: Introdução ao movimento ondulatório. Movimentos Oscilatórios, Ondas Mecânicas e Eletromagnéticas. Conceitos de Óptica Geométrica, Óptica Física e Acústica. Estudo analítico dos fenômenos naturais e simulações em laboratório.

Fonte: <http://www.mackenzie.br/17559.html>. Acesso em: 10 set. 2009

Durante o $5^{\circ}$ e o $6^{\circ}$ semestres, são oferecidas as disciplinas de Física Matemática I e II que, pelo nome, sugerem uma articulação entre a física e a matemática, mas, embora os conteúdos matemáticos apresentados nas ementas sejam relevantes para o estudo de física, não há, em suas ementas, nenhuma referência que leve em consideração um trabalho realmente articulado entre os conteúdos matemáticos mencionados e o ensino da disciplina de física. Estas considerações podem ser verificadas no Quadro 11.

Quadro 11. Ementa das disciplinas Física Matemática I e II, da IES 17

Disciplina: Física Matemática I

Ementa: Séries Infinitas. Séries de Potências; Números Complexos. Séries de Potências Complexas; Funções Fatoriais, Gama e Beta; Funções de Bessel e Legendre; Equações Diferenciais Parciais.

Disciplina: Física Matemática II

Ementa: Séries de Fourier. Forma Complexa da Série de Fourier; Integrais de Fourier. Transformadas de Fourier; Transformadas de Laplace; Resolução de Equações Diferenciais utilizando as Transformadas de Laplace; Equações Diferenciais de Hermite e Laguerre.

Fonte: <http://www.mackenzie.br/17559.html>. Acesso em: 10 set. 2009

A análise das ementas revela grande preocupação dessa IES com o tratamento dos conteúdos de física, que não são apresentados apenas em caráter de revisão, mas recebem o devido aprofundamento. Apesar de as disciplinas Física Matemática I e II apresentarem conteúdos importantes da matemática a serem utilizados na física, não ocorrem articulações entre estas duas disciplinas. Dentre as IES aqui analisadas, esta é a que dá mais enfoque às disciplinas da área de física no curso de licenciatura em matemática. 


\section{Considerações finais}

Em se tratando dos cursos de formação de professores que ensinam física, os dados são preocupantes. No Brasil, existe atualmente um número bastante pequeno de professores formados na disciplina específica de física e, segundo os dados levantados, esse número não é suficiente para atender à demanda de professores para essa disciplina. Verificamos problemas relacionados à pouca quantidade de ingressantes e, destes, uma pequena quantidade de concluintes, o que indica que pouco se tem formado de professores com habilitação específica para ministrar a disciplina de física.

Os dados coletados pelo MEC/Inep revelam que uma significativa parcela de professores que atualmente ministram a disciplina de física tem formação específica em matemática. A análise que realizamos das 27 instituições de Ensino Superior distribuídas pelo Brasil - suas ementas e a carga horária reservada à disciplina de física nos cursos de licenciatura em matemática - nos leva a crer que grande parcela dos professores que ministram a disciplina de física e realizaram o curso de licenciatura em matemática não tem formação adequada para esse trabalho, uma vez que, nos cursos de licenciatura em matemática, as disciplinas de física contemplam aspectos do conteúdo, porém muitas vezes desvinculados de aulas práticas (laboratório) e, também, sem abordar os aspectos didáticos do conteúdo a ensinar.

As aulas de laboratório, imprescindíveis para o entendimento dos conceitos físicos, não estão incluídas nas ementas ou nos projetos pedagógicos das instituições privadas, o que nos leva a entender que os futuros professores aprendem conteúdos desvinculados de suas práticas.

Além disso, a disciplina de física tem uma carga horária bastante reduzida, e não há articulação entre os conceitos de matemática e de física trabalhados durante o curso, o que impede que os futuros professores compreendam suas interfaces ou relacionamentos. Devido a uma carga horária reduzida, os conteúdos de física são apresentados de forma fragmentada, tendo seu foco na Mecânica. Ao que tudo indica, as ementas são elaboradas com base na retomada de alguns conteúdos de física aprendidos no Ensino Médio, sem maiores aprofundamentos e sem criar relações com áreas afins. Assim, o problema parece ser bem maior do que a falta de professores para uma área específica: é, antes, relacionado à formação dos que ministram esta disciplina na rede de Ensino Médio.

Em relação, ainda, aos conteúdos, apenas em uma das instituições pesquisadas existe a preocupação em oferecer disciplinas optativas que abordem o ensino de física e conteúdos relacionados à física moderna e contemporânea, tópicos estes de grande relevância e trabalhados atualmente no Ensino Médio.

Os dados são preocupantes, quando levamos em consideração a forma como tem sido ensinada a disciplina de física na fase de escolarização do Ensino Médio, uma vez que a formação dos professores não tem sido adequada para esta finalidade e a formação dos professores de matemática deve prepará-los para ministrar a disciplina de matemática, e não de física. Contudo, é preciso considerar que, historicamente, estas duas disciplinas têm um papel articulado, e isso não tem sido levado em consideração nem na Educação Básica, nem no Ensino Superior.

Além disso, os dados quantitativos apresentados neste artigo revelam que muitos professores de física são formados nos cursos de licenciatura em matemática; e, se permane- 
Santos, C. A. B.; Curi, E.

cer essa demanda de alunos para o Ensino Médio, serão necessários vinte anos para que os licenciados em física assumam o ensino dessa área do conhecimento. Cabe lembrar que o Ensino Médio está em expansão, e a tendência é ampliar a necessidade quantitativa de professores de física.

Mediante a situação apresentada e a perspectiva para os próximos anos, é urgente repensar sobre o enfoque das disciplinas de física nos cursos de licenciatura em matemática, tanto na seleção e na organização dos conteúdos como no tratamento destinado a eles; e cuidar da formação do professor, que, embora venha a ser um professor de matemática, atuará, muitas vezes, como professor de física.

\section{Referências}

INSTITUTO NACIONAL DE ESTUDOS E PESQUISAS EDUCACIONAIS ANÍSIO TEIXEIRA. Censo do ensino superior 2007. Brasília : Inep, 2009a. Disponível em: $<$ http://portal.inep.gov.br/web/censo-da-educacao-superior/resumos-tecnicos $>$. Acesso em: 10 set. 2009.

Estudo exploratório sobre o professor brasileiro com base nos resultados do censo escolar da educação básica 2007. Brasília: Inep, 2009b. Disponível em: < http:// download.inep.gov.br/download/censo/2009/Estudo_Professor_1.pdf>. Acesso em: 06 out. 2009.

Sinopse estatística sobre o professor: censo escolar 2007. Brasília: Inep, 2009c. Disponível em: <http://portal.inep.gov.br/basica-censo-escolar-sinopse-sinopse>. Acesso em: 10 set. 2009.

PONTE, J. P. Concepções dos professores de matemática e processos de formação. In: (Ed.). Educação matemática: temas de investigação. Lisboa: Instituto de Inovação Educacional, 1992. p. 185-239. Disponível em: <www.educ.fc.ul.pt/docentes/ jponte/docs-pt/92-Ponte(Ericeira).doc>. Acesso em: 5 jun. 2003.

SANTOS, C. A. B. O ensino da física na formação do professor de matemática. 2010. 189 f. Tese (Doutorado em Ensino de Ciências e Matemática) - Universidade Cruzeiro do Sul, São Paulo, 2010.

SÃO PAULO (Estado). Lei complementar $\mathrm{n}^{\circ} 444$ de 27 de dezembro de 1985. Dispõe sobre o Estatuto do Magistério Paulista e dá providências correlatas. São Paulo: Secretaria de Estado da Educação, 1985.

. Indicação CEE no 53/2005 - CES - Aprovada em 14 de dezembro de 2005. Orientação ao Sistema Estadual de Ensino a respeito da qualificação necessária dos docentes para ministrar aulas das disciplinas do currículo da educação básica. Diário Oficial do Estado de São Paulo, São Paulo, 16 dez. 2005a. Seção 1, p. 46-49. 
A formação dos professores que ensinam física...

SÃO PAULO (Estado). Resolução $\mathrm{SE} \mathbf{n}^{\circ} \mathbf{9 0}$, de 9 de dezembro de 2005. Dispõe sobre o processo anual de atribuição de classes e aulas ao pessoal docente do quadro do magistério. São Paulo, 2005b. Disponível em: <http://siau.edunet.sp.gov.br/ItemLise/arquivos/notas/ 90-05.HTM?Time=2/15/2010\%207:33:38\%20PM>. Acesso em: 15 mar. 2009.

SHULMAN, L. S. Those who understand: knowledge growth in teaching. Educational Research, Oxfordshire, v. 15, n. 2, p. 4-14, 1986.

TARDIF, M. Saberes docentes e formação profissional. Petrópolis: Vozes, 2002. 